\title{
The away neurology rotation Is the grass greener on the other side?
}

\author{
Beau M. Ances, MD, PhD
}

\begin{abstract}
Medical students and residents often struggle with the pros and cons of pursuing an away rotation. The purpose of this article is to share personal perspectives on the benefits and costs of an away rotation.

NEUROLOGY 2006;66:E35-E36
\end{abstract}

Advantages of an away rotation. A common reason to consider an away rotation is the availability of training or expertise at an outside institution that cannot be afforded elsewhere. ${ }^{1}$ Often this rotation allows the individual to gain a fresh perspective for approaching particular medical problems. Although medicine consists of certain undeniable facts, it still is an art open to varying interpretations. By visiting other institutions, the individual can combine techniques learned from site(s) and create a new approach for solving complex medical problems. Visiting an outside site affords the medical student or resident the ability to gain this fresh perspective.

By pursuing an away rotation, a medical student or resident also has the opportunity to develop deeper bonds and interactions with particular leaders at other institutions. Relationships can be fostered that may assist the future applicant in employment opportunities. $^{2}$

Disadvantages of an away rotation. As anyone who has considered an away rotation knows, there are logistical issues that require considerable thought prior to initiating an away rotation.
Additional cost may be of primary concern to the trainee. ${ }^{3}$ Costs that may incurred by the applicant include housing, parking, travel, food, and medical insurance coverage.

The applicant should inquire from his or her home institution whether funds are available to defray some of these expenses. In addition, if the applicant is pursuing a research elective, outside funding sources may be available, depending on the field of interest. At the present time, neither the American Academy of Neurology (AAN) nor the American Neurological Association currently provides funding opportunities for away rotations (www.aan.com and www.aneuroa.org).

In addition to financial concerns, extensive time and energy are required to plan the rotation. The Accreditation Council for Graduate Medical Education (ACGME) duty hour regulations may limit an institution's ability to offer outside residents the rotations that they may request. When the rotations do become available, issues such as rescheduling clinics, coverage of patients by other residents, and obtaining temporary privileges must resolved.

Both the ACGME and the Neurology Residency Review Commit- tee (RRC) require documentation of all rotations. Residents and administrators at the home institution should be aware of these requirements before planning the away rotation. Currently, neither the ACGME nor the RRC has defined core requirements for an away rotation. In addition, no information exists on the number of residents who pursue away rotations or their experiences (personal communication with ACGME administrative offices, November 2005).

Possible timeline for an away rotation. An interested individual should contact members within the administration at the home institution early on concerning the possibilities of away rotations and the logistics involved. Next, the medical student or resident should contact key members at an outside institution(s) concerning the feasibility of pursing an away rotation. Once an agreement has been reached with the outside institution, all necessary paperwork should be completed prior to starting the away rotation. Inquiries should be made concerning the ability to examine patients during away rotations as differences can exist. A primary advisor should also be designated, with this individual

From the Department of Neurosciences and Radiology, University of California at San Diego, San Diego, CA.

Disclosure: The author reports no conflicts of interest.

Received September 23, 2005. Accepted in final form February 28, 2006.

Address correspondence and reprint requests to Dr. Beau M. Ances, HIV Neurobehavioral Research Center, 150 W. Washington, 2nd Floor, San Diego, CA 92119; e-mail: bances@ucsd.edu

Copyright () 2006 by AAN Enterprises, Inc. E35 
serving as not only an overseer of the rotation but also a conduit for contacting others at the outside institution. Discussions with this outside advisor should entail certain defined goals (either core clinical competencies or particular techniques or research skills) that should be achieved during the away rotation. By defining these goals early in the process, a more tailored and rewarding experience can be obtained.

A minimum of at least 3 weeks and preferably 4 weeks should be devoted to the away rotation. A considerable period of time maybe required for getting acclimated to the various nuances of the new facilities. During the rotation, time should be also be afforded to meet key individuals at the away site.

Recommendations for greater standardization for pursuing away rotations. An away rotation can be a rewarding experience that can build new knowledge and help a trainee develop long-lasting relationships. Currently, there is little to no formal guidance from the trainee governing bodies regarding away rotations. Although the AAN's recent attempt to institute a case log for all neurology residents was unsuccessful, it may be beneficial to consider a mechanism for documenting away rotation experiences. In particular, such documentation could provide valuable information on which programs participate in away rotations and which rotations are being successfully completed. A resident network to share information might be highly valuable.

\section{References}

1. Al-Sultan AI, Parashar SK, Al-Ghamdi AA. Electives during medical internship. Saudi Med J2003;24:1006-1009.

2. Tzarnas CD, Fessenden J. Audition electives during surgical residency and selection for post-residency fellowship positions. Curr Surg 2002;59:412-415.

3. Mittal V, Salem M, Tyburski J, et al. Residents' working hours in a consortium-wide surgical, education program. Am Surg 2004; 70:127-131 


\section{Neurology}

\section{The away neurology rotation: Is the grass greener on the other side? Beau M. Ances \\ Neurology 2006;66;E35-E36 \\ DOI 10.1212/01.wnl.0000216845.66742.9b}

\section{This information is current as of May 8, 2006}

\section{Updated Information \&} Services

References

Subspecialty Collections

Permissions \& Licensing

Reprints including high resolution figures, can be found at: http://n.neurology.org/content/66/9/E35.full

This article cites 3 articles, 0 of which you can access for free at: http://n.neurology.org/content/66/9/E35.full\#ref-list-1

This article, along with others on similar topics, appears in the following collection(s):

All Education

http://n.neurology.org/cgi/collection/all_education

Information about reproducing this article in parts (figures,tables) or in its entirety can be found online at:

http://www.neurology.org/about/about_the_journal\#permissions

Information about ordering reprints can be found online:

http://n.neurology.org/subscribers/advertise

Neurology ${ }^{\circledR}$ is the official journal of the American Academy of Neurology. Published continuously since 1951, it is now a weekly with 48 issues per year. Copyright . All rights reserved. Print ISSN: 0028-3878. Online ISSN: 1526-632X.

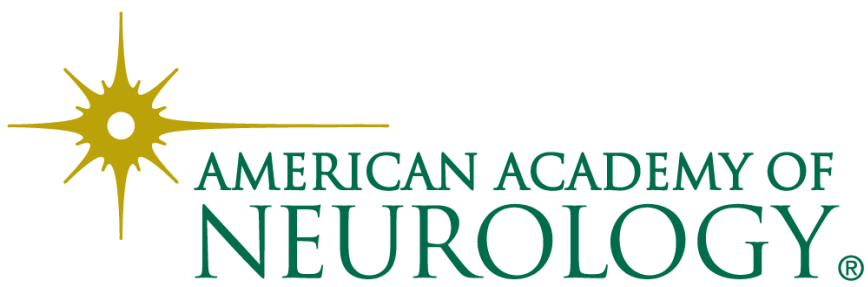

